\title{
Rancang Bangun Sistem Informasi Manajemen Aset pada Universitas Pamulang Berbasis Web
}

\author{
Joko Riyanto \\ Teknik Informatika, Fakultas Teknik, Universitas Pamulang, Jl. Surya Kencana No.1 Pamulang Barat, \\ Tangerang Selatan, Indonesia \\ e-mail: jokoriyanto@unpam.ac.id
}

\begin{abstract}
Pamulang University is a private tertiary institution located in South Tangerang City. Pamulang University has many assets to support its activities. At present the Pamulang University does not yet have an internal information system to control the assets owned. The absence of an asset management information system will certainly have difficulties in tracking asset data. Solutions to overcome existing problems, of course, require an asset management information system that can run asset management to be more efficient and structured, as well as facilitate data collection of assets, asset data based on conditions, asset groupings by type and facilitate tracking of asset data. the method used in developing the system is waterfall. This model consists of requirements analysis, system and software design, implementation and unit systems, system testing, operation and maintenance. With the existence of an asset management information system, it can provide easy management of assets at the University of Pamulang.
\end{abstract}

Keywords: asset management information system, web, waterfall

\section{Pendahuluan}

Perguruan tinggi merupakan suatu institusi yang sangat kompleks dalam menjalankan kegiatannya, tentu saja dibutuhkan penerapan Computer Based Information System (CBIS). CBIS adalah sebuah sistem yang memanfaatkan komputer untuk mengolah data yang kompleks menjadi informasi yang berguna (Laudon, 2008). Pada umumnya, suatu perusahaan atau institusi tentunya telah memiliki sistem yang digunakan untuk menunjang kegiatannya, begitu juga halnya dalam pengelolaan aset.

Aset adalah segala sesuatu yang berwujud maupun tak berwujud yang mana memiliki nilai ekonomi dan masa ekonomis guna mendukung kegiatan operasional instansi atau organisasi. Sedangkan manajemen aset adalah sebuah kegiatan merencanakan, pengawasan dan pengorganisasian dalam menggunakan, memperbaiki, merawat dan membeli serta menghilangkan aset secara fisik guna memaksimalkan pelayanan dan mengurangi biaya serta resiko dalam mengelola aset berwujud maupun tak berwujud dengan atau tanpa teknologi dalam menjalankan kegiatan operasional (Lembaga Administrasi Negara, 2007). Kebutuhan akan sistem informasi untuk mengelola data dari aset-aset institusi yang ada sangatlah penting guna menunjang operasional suatu institusi tersebut, tidak adanya sistem informasi dan data yang valid dalam mengelola aset tentu saja membuat pengelolaan serta laporan data aset menjadi tidak seimbang dan dapat menghambat kegiatan operasional.

Universitas Pamulang adalah perguruan tinggi yang terletak di Kota Tangerang Selatan di mana memiliki sarana dan prasarana di tiga lokasi berbeda. Tentu Universitas Pamulang memiliki aset-aset sebagai penunjang kegiatannya seperti meja, kursi, papan tulis, komputer, printer, dan yang lainnya. Saat ini Universitas Pamulang belum memiliki sistem internal yang dapat mengontrol aset-aset yang dimiliki. Belum adanya sistem informasi manajemen aset tersebut tentu menyebabkan kesulitan dalam pengelolaan datadata asset dalam merencanakan, memperbaiki maupun pada saat membeli asset baru. Permasalahan tersebut dapat menyebabkan pengelola aset kesulitan dalam melakukan pendataan jumlah aset, pendataan kondisi aset itu baik, rusak, ataupun dalam keadaan hilang dan pengelompokan aset berdasarkan jenisnya. Hal tersebut dapat menyebabkan proses laporan aset serta penggantian aset yang rusak pada Universitas Pamulang ini menjadi tidak maksimal. Solusi untuk mengatasi permasalahan yang ada, tentunya perlu sebuah sistem informasi dalam pengelolaan aset yang dapat memudahkan manajemen dalam mengelola aset menjadi lebih efisien, efektif, dan 
terstruktur. Diharapkan dengan dibangunnya sistem infomasi manajemen aset ini, dapat memudahkan pengelola aset untuk melakukan pengelolaan dan pendataan aset yang ada pada Universitas Pamulang.

\section{Metode Penelitian}

\subsection{Metode Pengumpulan Data}

Data yang diperlukan sebagai informasi dan bahan masukan dalam penelitian ini adalah dengan menggunakan data primer maupun data sekunder, adapun untuk mendapatkanya dengan beberapa metode antara lain:

\section{a. Studi Literatur}

Merupakan metode yang bersumber pada buku, jurnal, dan sumber bacaan lainnya. Pada umumnya metode ini dilakukan dengan cara mencari, menelaah dan membandingkan penelitian sebelumnya yang berkaitan dengan sistem informasi manajemen aset.

b. Observasi

Merupakan metode yang dilakukan dengan cara datang ke lokasi yang dijadikan tempat pengambilan sampel. Dalam hal ini adalah objek penelitian ataupun permasalahan yang terdapat pada proses kegiatan pengelolaan aset sehingga didapat suatu data yang otentik dan jelas. Pada umumya metode ini dipergunakan saat melakukan analisa pada data yang telah diperoleh ataupun terhadap permasalahan yang ada dan pada saat implementasi dan testing sistem.

c. Wawancara

Merupakan sebuah metode yang dilakukan dengan cara tanya jawab terhadap sumbersumber terkait dengan tujuan untuk memperoleh data-data yang diperlukan oleh peneliti atau tanya jawab terhadap data-data yang kurang dimengerti sehingga didapat kebenarannya pada data tersebut. Pada umumnya metode ini lebih banyak digunakan pada saat sebelum melakukan kegiatan perancangan sistem manajemen asset ini.

\subsection{Metode Pengembangan Sistem}

Model pengembangan sistem yang digunakan dalam penelitian ini adalah model waterfall yang ditunjukkan pada Gambar 1 . Terdapat lima tahapan dalam waterfal, antara lain:

a. Analisis Kebutuhan

Dalam tahap ini melakukan identifikasi kebutuhan sistem yang sesuai dengan harapan pengguna dan menganalisa sistem yang sedang berjalan saat ini untuk menganalisa kebutuhan guna mendapatkan solusi dari permasalahan. Data-data yang dibutuhkan pada tahapan ini biasanya diperoleh melalui wawancara maupun observasi.

b. Perancangan dan Desain Sistem

Dalam tahap perancangan dan desain sistem ini adalah dengan cara melakukan desain sistem untuk memecahkan permasalahan yang terjadi di mana peneliti merancang sistem berorientasi objek menggunakan Unifield Modeling Language (UML) sebagai pemodelan sistem serta Entity Relationship Diagram (ERD) sebagai gambaran struktur dan relasai data sesuai dengan kebutuhan yang diperlukan.

c. Implementasi dan Pengujian Unit

Dalam tahap ini peneliti melakukan kegiatan pemrograman atau merancang sistem informasi untuk pengelolaan aset sesuai dengan desain sistem yang telah dirancang sebelumnya.

Pembuatan aplikasi terdiri unit atau submodul yang kemudian digabungkan menjadi modul yang utuh (Munawar, 2005). Dalam setiap modul-modul kecil itu dilakukannya pengujian untuk mengetahui apakah sistem yang dikembangkan sudah berjalan sesuai dengan fungsi yang diinginkan.

d. Pengujian Sistem

Pada tahap ini dilakukan pengujian menggunakan metode pengujian white box di mana peneliti melakukan pengecekan kodekode program PHP yang telah dibuat dan pengujian black box untuk melakukan pengecekan hasil keluaran dari aplikasi, apabila hasil keluaran tidak sesuai atau terjadi kesalahan maka akan dilakukannya perbaikan agar hasil keluar dari program sudah sesuai dengan yang diharapkan.

e. Instalasi dan Pemeliharaan Sistem

Instalasi dan pemeliharaan sistem adalah tahap akhir dalam model waterfall. Aplikasi yang telah dikembangkan diinstalasi untuk bias digunakan dan kemudian pada proses pemeliharaan aplikasi dengan cara melakukan perbaikan-perbaikan terhadap modul sistem yang belum berjalan sesuai keinginan pihak institusi. 


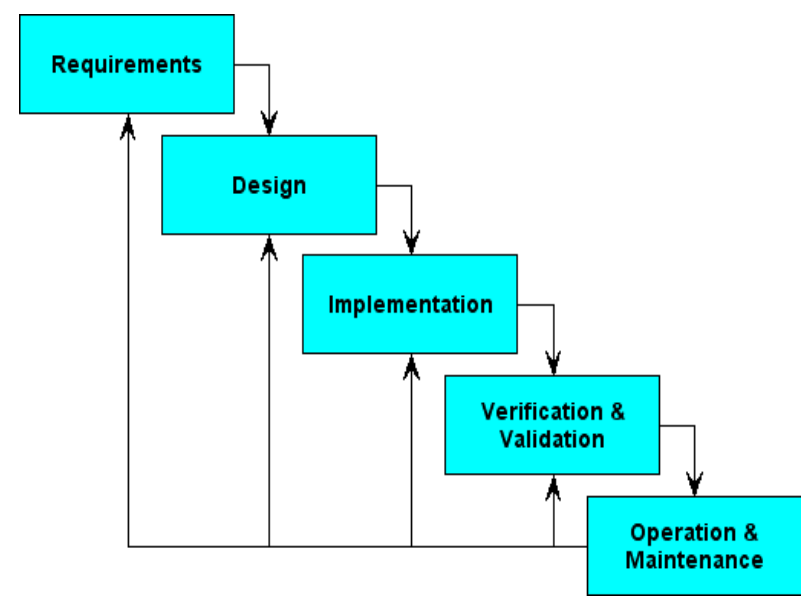

Gambar 1 Metode Pengembangan Waterfall

\section{Hasil dan Pembahasan}

\subsection{Analisa Sistem Saat Ini}

Pada saat ini Universitas Pamulang belum memiliki sistem informasi internal untuk mengontrol aset-aset yang dimiliki. Belum adanya sistem manajemen aset tersebut tentu akan mengalami kesulitan dalam penelusuran data-data aset. Permasalahan tersebut dapat menyebabkan pengelolaan aset kesulitan dalam melakukan pendataan jumlah aset, pendataan kondisi aset, dan pengelompokan aset berdasarkan jenisnya. Hal tersebut dapat menyebabkan proses laporan aset serta penggantian aset yang rusak menjadi tidak maksimal.

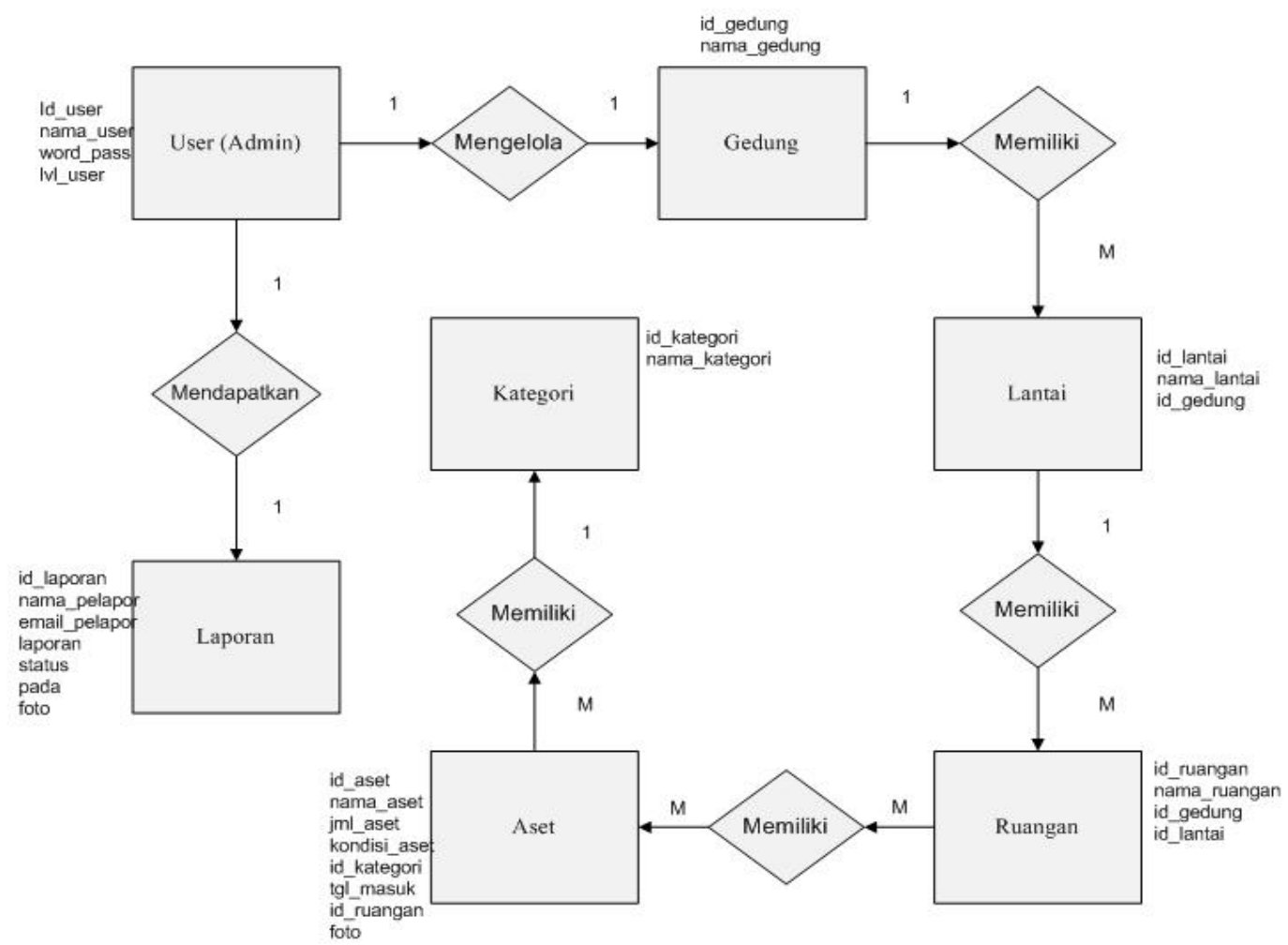

Gambar 2 Entity Relationship Diagram

\subsection{Analisa Sistem Usulan}

Untuk mengatasi permasalahan yang ada maka diperlukan aplikasi yang dapat melakukan pengelolaan data aset, dimulai dari proses pengalokasian barang atau aset sampai pada proses pelaporan terhadap kondisi aset. Sistem manajemen aset yang dibuat ini menggunakan basis data yang berfungsi untuk menyimpan data dengan jumlah yang banyak. Dengan sistem manajemen aset ini diharapkan dapat memberikan kemudahan dalam pendataan jumlah aset, pendataan aset berdasarkan kondisi aset, dan pengelompokan asset berdasarkan jenisnya. Sistem manajemen aset ini juga dirancang untuk dapat melakukan laporan terhadap kondisi aset yang ada, sehingga diharapkan dapat memberikan kemudahan terhadap pengelola aset dalam melakukan penelusuran data-data aset. Berikut adalah secara umum fitur yang akan dibuat dalam sistem usulan meliputi: 
a. Admin dan teknisi mempunyai hak akses account yang berbeda untuk login ke dalam aplikasi.

b. Admin dapat melakukan pengelolaan data gedung, lantai, kelas, aset, dan jenis aset.

c. Teknisi dapat melakukan pengelolaan terhadap kondisi aset.

d. Aplikasi ini dilengkapi fitur untuk pelapor dalam membuat laporan terhadap kondisi aset yang ada.

e. Laporan yang telah dibuat oleh pelapor dikirimkan kepada admin dan teknisi.

f. Terdapat fitur rekap data-data aset yang dapat dilihat dan dicetak oleh admin atau teknisi berdasarkan pengalokasian aset dan kondisi aset.
Adapun proses data informasi dalam sistem manajemen aset yang akan dirancang terdiri dari tiga pengguna yaitu admin, teknisi, dan pelapor.

\subsection{Entity Relationship Diagram (ERD)}

ERD merupakan sebuah diagram yang menggambarkan relasi antarentitas data (Fathanysah, 2012). Entity Relationship Diagram dari aplikasi yang akan dikembangkan ditunjukkan pada Gambar 2.

\subsection{Use Case Diagram}

Use case merupakan penjelasan atau gambaran interaksi yang terjadi antara aktor atau pengguna dengan inisiator dari hubungan sistem yang ada. Use case dari sistem informasi manajemen aset ditunjukkan pada Gambar 3.

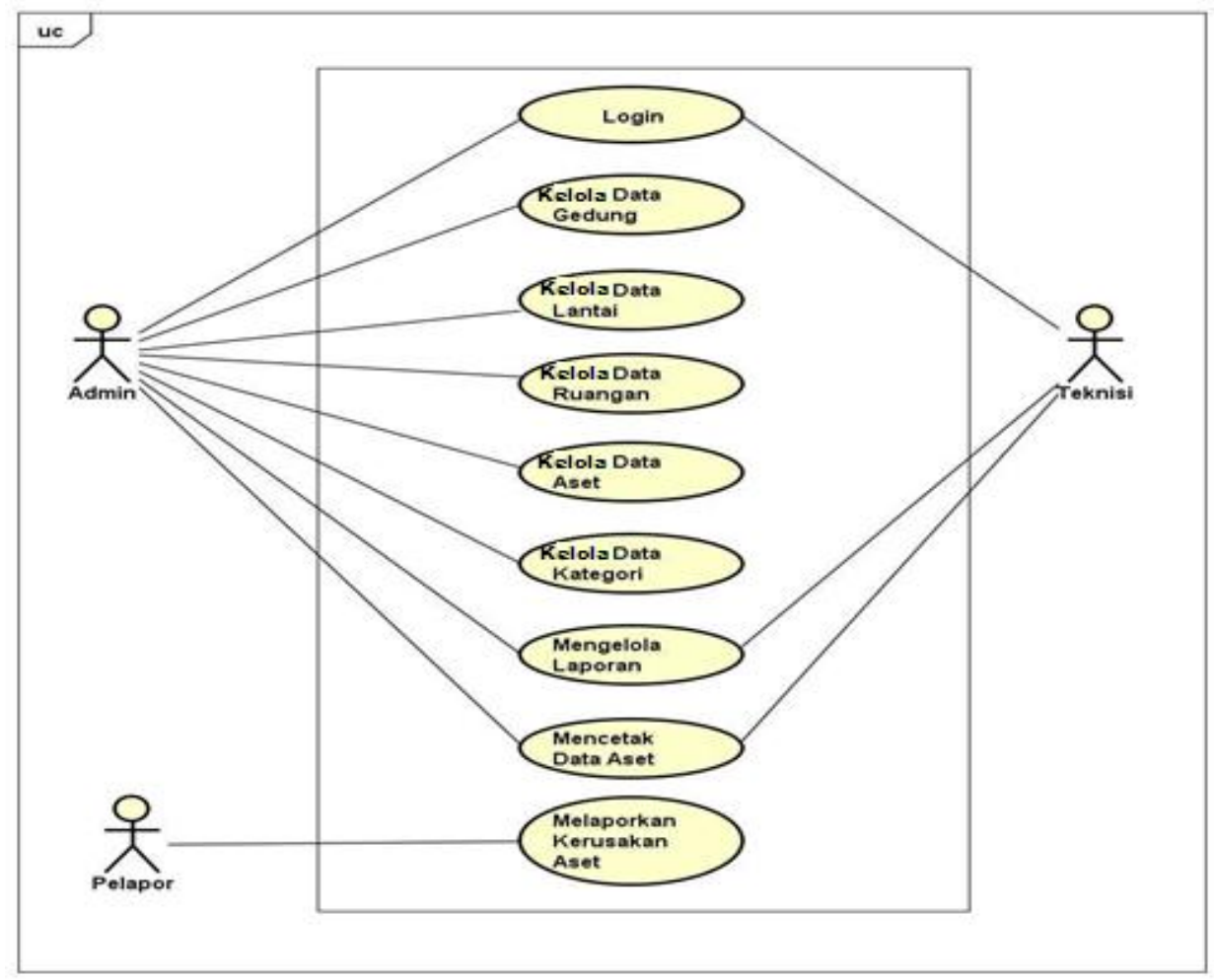

Gambar 3 Use Case Diagram

Activity Diagram adalah teknik mendeskripsikan logika procedural (Munawar, 2005). Activity diagram input data aset dari sistem informasi manajemen aset yang akan dikembangkan ditunjukkan pada Gambar 4. Gambar tersebut menjelaskan kegiatan admin dalam memasukkan data asset ke form input data aset yang kemudian disimpan ke dalam database. Sehingga data akan tampil dalam form daftar aset. Dalam form ini juga data dapat diedit, dan dihapus.

\subsection{Implementasi dan Pengujian}

Setelah tahap perancangan selesai dilanjutkan dengan tahap penerapana atau implementasi (Fathanysah, 2012). Penerapan sistem merupakan tahap development perangkat lunak yang disesuaikan dengan hasil perancangan. Tahap penerapan sistem merupakan aktivitas menerjemahkan hasil perancangan sistem ke dalam bahasa pemrograman yang digunakan dan dapat dimengerti oleh mesin. 


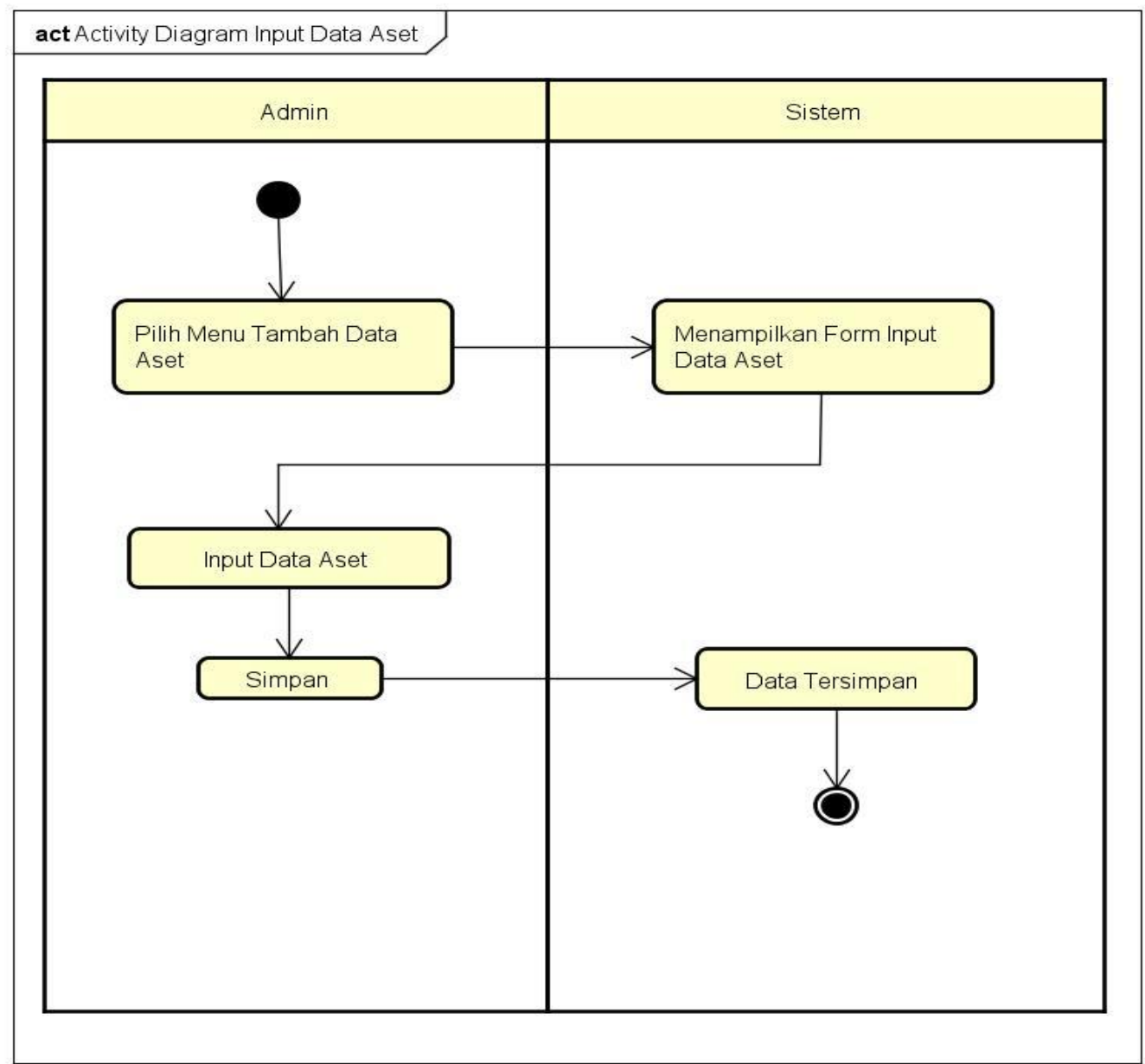

Gambar 4 Activity Diagram Input Data Aset

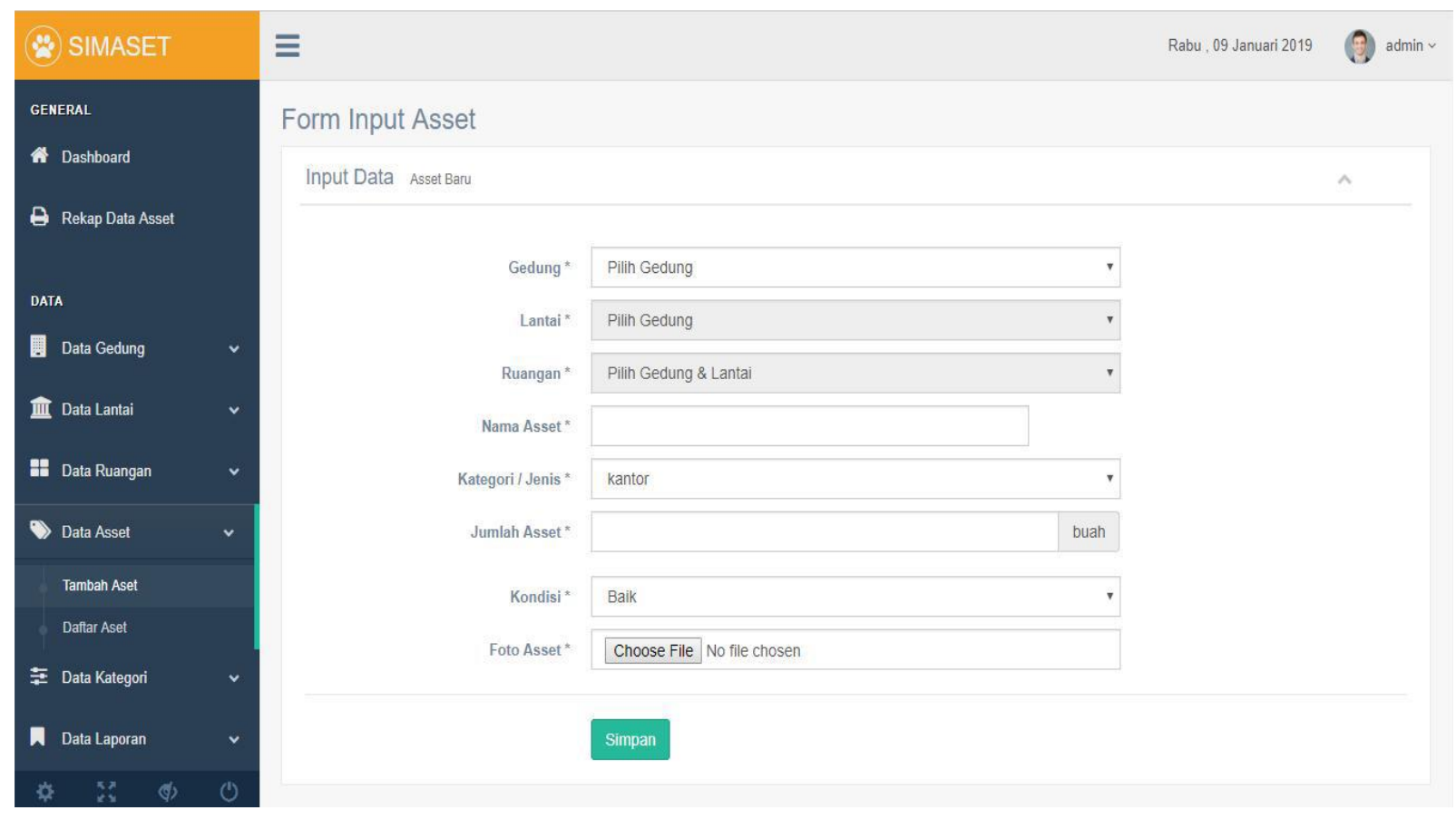

Gambar 5 Tampilan Tambah Data Aset 


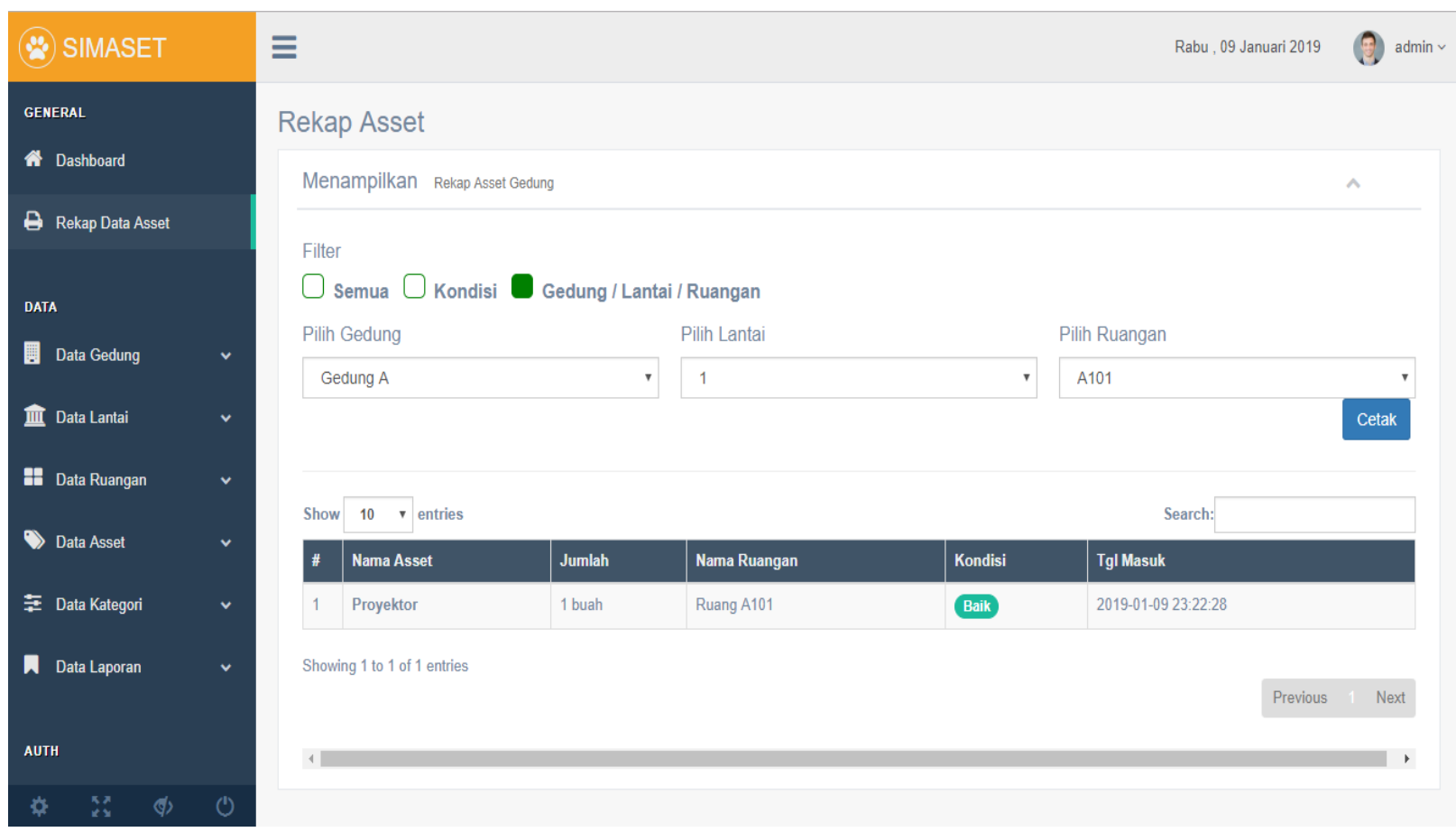

Gambar 6 Tampilan Rekap Data Aset

Pengujian sistem merupakan suatu proses pengujian terhadap kelayakan dan kualitas aplikasi yang telah dibuat. Dalam tahapan ini terdapat dua jenis pengujian yaitu pengujian black box dan white box. Pengujian black-box merupakan jenis pengujian yang bersifat fungsional dari sistem, untuk memastikan bahwa sistem yang dibuat sudah sesuai dengan keinginan dari pengguna tanpa ada kesalahan (Rizky, 2011). Berikut adalah hasil pengujian black box dari sistem manajemen aset ini.

Tabel 1 Pengujian Black Box pada Halaman Login

\begin{tabular}{|c|c|c|c|}
\hline Deskripsi & Hasil yang Diharapkan & Hasil Pengujian & Kesimpulan \\
\hline $\begin{array}{l}\text { Admin input username } \\
\text { serta password yang } \\
\text { benar. }\end{array}$ & $\begin{array}{l}\text { Sistem akan menampilkan } \\
\text { halaman utama }\end{array}$ & $\begin{array}{l}\text { Berhasil login dan sistem } \\
\text { menampilkan halaman } \\
\text { utama. }\end{array}$ & $\begin{array}{l}\text { ( } \sqrt{ } \text { ) Diterima } \\
\text { ( ) Ditolak }\end{array}$ \\
\hline $\begin{array}{l}\text { Mengisi username dan } \\
\text { password yang salah }\end{array}$ & $\begin{array}{l}\text { Sistem akan menolak akses } \\
\text { login dan menampilkan } \\
\text { pesan "user tidak ditemukan" }\end{array}$ & $\begin{array}{l}\text { Sistem dapat menolak } \\
\text { akses login dan } \\
\text { menampilkan pesan “" } \\
\text { user tidak ditemukan”" }\end{array}$ & $\begin{array}{l}\text { ( } \sqrt{ } \text { ) Diterima } \\
\text { ( ) Ditolak }\end{array}$ \\
\hline $\begin{array}{l}\text { Mengosongkan } \\
\text { username dan } \\
\text { langsung menekan } \\
\text { tombol login }\end{array}$ & $\begin{array}{l}\text { Sistem akan menolak akses } \\
\text { login dan menampilkan } \\
\text { pesan" username harus diisi" }\end{array}$ & $\begin{array}{l}\text { Sistem dapat menolak } \\
\text { akses login dan } \\
\text { menampilkan pesan } \\
\text { "username harus di isi" }\end{array}$ & $\begin{array}{l}\text { ( } \sqrt{ } \text { ) Diterima } \\
\text { ( ) Ditolak }\end{array}$ \\
\hline $\begin{array}{l}\text { Mengosongkan } \\
\text { password dan } \\
\text { langsung menekan } \\
\text { button login }\end{array}$ & $\begin{array}{l}\text { Sistem akan menolak akses } \\
\text { login dan menampilkan } \\
\text { pesan "password harus diisi" }\end{array}$ & $\begin{array}{l}\text { Sistem dapat menolak } \\
\text { akses login dan } \\
\text { menampilkan pesan } \\
\text { "password harus di isi" }\end{array}$ & $\begin{array}{l}\text { ( } \sqrt{ }) \text { Diterima } \\
\text { ( ) Ditolak }\end{array}$ \\
\hline
\end{tabular}


Tabel 2 Pengujian Black Box pada Tambah Aset

\begin{tabular}{|l|l|l|c|}
\hline \multicolumn{1}{|c|}{ Deskripsi } & \multicolumn{1}{|c|}{ Hasil yang Diharapkan } & \multicolumn{1}{c|}{ Hasil Pengujian } & Kesimpulan \\
\hline $\begin{array}{l}\text { Admin input data aset } \\
\text { dengan mengisi semua } \\
\text { data dan menekan } \\
\text { tombol simpan }\end{array}$ & $\begin{array}{l}\text { Menginput data aset dengan } \\
\text { mengisi semua field, maka } \\
\text { sistem dapat menyimpan data } \\
\text { dan menampilkan pesan " } \\
\text { data berhasil disimpan" } \\
\text { kemudian pada list data aset } \\
\text { akan bertambah }\end{array}$ & $\begin{array}{l}\text { Sistem dapat } \\
\text { menyimpan data aset, } \\
\text { dan sistem dapat } \\
\text { menampilkan pesan } \\
\text { "data berhasil disimpan" } \\
\text { kemudian pada list data } \\
\text { aset bertambah }\end{array}$ & $\begin{array}{c}\text { ( } \text { ( ) Diterima } \\
\text { ( ) Ditolak }\end{array}$ \\
\hline $\begin{array}{l}\text { Admin mengosongkan } \\
\text { data asset kemudian } \\
\text { menekan tombol } \\
\text { simpan }\end{array}$ & $\begin{array}{l}\text { Sistem akan menolak dengan } \\
\text { memberikan informasi pesan } \\
\text { "Data aset harus diisi" }\end{array}$ & $\begin{array}{l}\text { Sistem dapat menolak } \\
\text { dengan memberikan } \\
\text { informasi pesan "Data } \\
\text { aset harus diisi" }\end{array}$ & $\begin{array}{l}\text { ( V) Diterima } \\
\text { ( ) Ditolak }\end{array}$ \\
\hline
\end{tabular}

Berdasarkan hasil pengujian di atas dapat diambil kesimpulan yang mana sistem manajemen aset yang telah dibangun memiliki fungsional yang baik dan bebas dari kesalahan serta memberikan hasil yang sesuai harapan.

\section{Kesimpulan}

Berdasarkan hasil implementasi dan analisa pengujian sistem yang telah dibuat dan dilaksanakan, maka disimpulkan sebagai berikut: a. Sistem informasi manajemen aset ini dibangun dengan model pengembangan waterfall, dan pemodelan perancangan sistem dengan UML, yang mana secara fungsional sesuai dengan yang diharapkan.

b. Dengan dikembangkannya sistem informasi manajemen aset ini dapat memberikan kemudahan pendataan jumlah aset, pendataan kondisi aset, dan pengelompokan asset berdasarkan jenisnya serta memudahkan dalam melakukan penelusuran data-data aset.

\section{Daftar Pustaka}

Fathanysah. (2012). "Model Data" di dalam Basis Data, rev. ed. Bandung: Informatika.

Lembaga Administrasi Negara. (2007). Dasar-Dasar

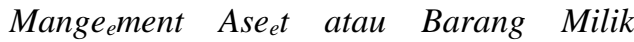
Daerah. Diklat Teknis Manajemen Aset Daerah.

Laudon, J.P., Laudon, K.C. (2008). Siistem I informasi $M_{a}$ anajemen edisi 10. Terje emahan Chri $i_{\mathrm{i} w a n}$ Sungko ${ }_{0}$ no dan Machmudin Eka P. Jakarta: Sale $\mathrm{mba}$ Empat

Munawar. (2005). Pemodelan Visual dengan UML. Yogyakarta: Graha Ilmu.

Purwaningtias, Fitri. 2015. $R_{a}$ ancang $B_{a} a n g u n$ $P_{e}$ engolahan Daata Penye ewaan Allat Ber $r a t$ $P a_{a} d a$ PT. Sumat ra Ung gul Pallembang. Palembang: Jurnal Informati ka. Vol. 1.

Pambudi, Galih. S., \& Ary, Arvianto. 2016. 'R $R_{a} a n c a n g$ ${ }^{\prime} B_{a}$ angun 'Sistem Informasi ${ }^{\mathrm{a}}$ Manajemen $A^{a}$ set Berabasis We $W^{e}$ untuuk Optimalisasi $P_{e}$ enelusuran $A_{s}$ set Di $T_{e} e k n i k$ Industr $r i$ Und $i$ ip. Semarang: $\mathrm{J}_{\mathrm{u}}$ urnal $\mathrm{T}_{\mathrm{e}}$ eknik Industri. Vol 11, No. 3.

Rizky, S. (2011). Konsep Dasar Rekayasa Perangkat Lunak. Jakarta: Prestasi Pustaka 